\title{
Designing a Reverse Logistics Network for an E-Commerce Firm: A Case Study
}

\author{
Debadyuti Das \\ Faculty of Management Studies \\ University of Delhi \\ Delhi - 110007 \\ E-mail: ddas@fms.edu (Corresponding Author) \\ Rahul Kumar \\ Faculty of Management Studies \\ University of Delhi \\ Delhi - 110007 \\ E-mail: rahulkumar886049@gmail.com \\ Manish Kumar Rajak \\ ShopClues \\ Gurugram, Haryana \\ E-mail: manish.r16@fms.edu
}

\begin{abstract}
The present work is an attempt to design a reverse logistics (RL) network for an e-commerce firm based on one of the most frequently returned items namely fashion goods. The problem essentially revolves around the trade-off between cost and responsiveness in designing an $\mathrm{RL}$ network for an ecommerce firm. We have considered several large neighborhoods in the northern capital region of India and treated the same as customer indexes from which the returns originate. Several candidate nodes have been identified as initial collection centers (ICCs) in which the returns from the customer indexes are initially collected and stored for some time before being sent to the final warehouses. There are three warehouses in three different cities. We have ensured that one customer index would be assigned to only one ICC. The decision variables of the above problem include the selection of ICCs, the assignment of the customer indexes to the ICCs and finally the volume of returns to be shipped from the ICCs to all three warehouses. We have formulated the above problem as a mixed integer linear programming (MILP) problem with a view to minimizing the total cost of the network. We have carried out sensitivity analyses on relevant parameters and provided rich managerial insights.
\end{abstract}

Keywords: Reverse logistics, e-commerce firm, costresponsiveness trade-off, mixed integer linear programming

\section{INTRODUCTION}

The concept of reverse logistics (RL) originated in traditional brick and mortar firms is influenced by both environmental and economic considerations as revealed in several research findings (Rogers and Tibben-Limbke, 1999; 2001; Guide and Van Wassenhove, 2009; Das and Chaudhari, 2015). The traditional physical stores have devised several mechanisms to incentivize customers for taking back the unused, end-of-life (EOL) and end-of-use (EOU) goods with a view to minimizing the possibility of disposal of the same in open environment thereby preventing adverse environmental impact. At the same time these organizations have made investment in physical infrastructure, logistics, technology and labor for the purpose of undertaking repair, refurbishment, remanufacturing in the returned items and also reclamation of components and materials from the same (Tanskanen, 2012; Weraikat et al., 2016; Atlason, Giacalone, and Parajuly, 2017). This infrastructure enables the firms to create a separate revenue stream for the refurbished goods and the retrieved components. Thus both environmental and economic factors serve as the motivating factors of RL in traditional firms. On the contrary, the motivation of RL in e-commerce firms is centered around mostly economic gains. Because one of the critical success factors of an e-commerce firm is its return policy, which is considered an important component of marketing strategy in online retail (Mukhopadhyay and Setoputro, 2004; Hjort and Lantz, 2016). Before initiating purchase from any e-commerce firm, a customer thoroughly evaluates its return policy. Thus it has become imperative for most of the e-commerce firms to offer a reasonable and hassle-free return policy in order to incentivize customers for increased purchase. At the same time, E-tailers have to commit significant amount of resources in designing a suitable network for collection, handling, storage and subsequent disposition of returns for achieving success (Xiao Yan et al., 2012; Liu, 2014; Zaarour et al., 2014). Ecommerce firms need to take back the returned items and replace the same with the desired ones if the items delivered turned out to be defective or different from the prescribed specifications. Volume of returns in an e-commerce firm constitutes a significant percentage of overall sales which seems to be much higher than the same observed in a traditional retail firm. One study finding reveals that the returns in e-commerce firms constitute at least $30 \%$ of all orders compared to only $8.89 \%$ returns in brick and mortar 
sales (E-commerce Product Return Statistics and Trends, 2016). This is a great challenge being faced by all ecommerce firms across the globe.

According to a global survey pertaining to the returns of e-commerce firms carried out in 2016, the most frequently returned items include clothing and accessories (75\%) followed by consumer electronics items $(33 \%)$ and then foot wear $(32 \%)$ (Share of consumers who returned items in 2016). The useful life of these items is relatively short because the items are time-sensitive in nature and the probability of obsolescence of these items is quite high. Thus these returned items need to be sent back to the vendors or need to be resold to other customers or other parties quickly in order to realize their salvage value. However, if the returns are sent back to the vendors through faster mode of communication in frequent interval for improving the marginal value of time and responsiveness, the cost of transportation becomes prohibitively high, although inventory carrying cost diminishes. On the contrary, if the returns are sent back to the vendors in batch mode through surface mode of transportation, cost of transportation would decrease due to economies of scale achieved in transportation. The flip side of this strategy includes higher inventory carrying cost, higher likelihood of obsolescence of the items due to declining marginal value of time of the items and poor responsiveness. Thus essentially the problem revolves around the trade-off between cost and responsiveness in designing a network for collection and disposition of returned goods with specific reference to timesensitive items.

Academic researchers have been trying to explore the above issues since the last decade. The earliest work includes an exploratory study on e-commerce for RL (Kokkinaki et al., 2000). The findings simply indicate the importance of $\mathrm{RL}$ in e-commerce firms and the replication of RL practices in these firms. Mukhopadhyay and Setoputro (2004) proposed a profit maximization model for an e-commerce firm to obtain optimal policies for price and the return policy in terms of certain market reaction parameters. Dissanayake and Singh (2007) argued that a good return management process supports customer relationship management and enables capturing value by reselling, and redistributing returned products. Weltevreden (2008) suggested the installation of collection and delivery points in nearby shopping centers and petrol pumps in order to avoid failed delivery or repeat delivery to home. Wang (2015) developed a decision model of returns logistics based on the behavior of customers on cost and time dimensions in e-commerce firms. Hjort and Lantz (2016) analyzed the impact of returns policies on profitability of a Swedish online fashion retailer. None of the above studies dealt with the RL network design which would clearly provide insights to the managers in terms of collection, storage, transportation and disposition of the returns.

There are a limited number of studies relating to the RL network design of e-commerce firms. For example, Yan et al. (2012) proposed a mixed integer linear programming (MILP) model considering RL network design of an ecommerce firm. The decision variables include several binary variables. These consist of whether to open a factory, an online retailer and a 3PL provider. The model did not account for the customer points from which returns emanate, neither did it consider the initial collection centers (ICCs) in which returns are brought and sorted before being finally sent to the warehouses. The model thus could not analyze the dynamics of cost-responsiveness trade-off considered very important in RL network design problem in an e-commerce firm. Liu (2014) developed a RL network site optimization model for an e-commerce firm based on genetic algorithm. The study determined the optimal number of collection points, recycling centers and remanufacturing centers. This model also failed to analyze the element of costresponsiveness trade-off while managing returns. Zaarour et al. (2014) developed a non-linear mixed integer model of RL network design for handling returns in an e-commerce firm for determining the optimal number and location of initial collection points, holding time of returns at the collection points and optimal number of final return centers. The model discusses the cost-responsiveness trade-offs between inventory carrying cost and transportation cost considering different holding periods for managing returns. However, the model seems to suffer from a major fundamental flaw. Determining the location and number of final return centers or warehouses is considered to be a strategic decision rather than a simple operations decision. The model suggested by Zaarour et al. (2014) recommends the setting up of final return centers based on the volume of returns from the collection points to the return centers. Das et al. (2018) introduced the problem of RL network design for an ecommerce firm. However, we did not come across the detailed findings of this work. The revelation of the above models suggests that there exist considerable gaps in logistics literature in terms of RL network design in an ecommerce firm.

With reference to Indian context, we have hardly come across any study on RL network design for e-commerce firms. For most online retailers in India, product returns roughly average around 20\% (KPMG Report: E-commerce retail logistics in India, 2018). Each time a customer returns a product, the e-tailing firm has to bear an average additional expenditure in transportation cost to send it back to the sellers or to the final warehouse. The amount of this shipping cost depends on the weight of the item, dimension of the same, distance between the pick-up zone and delivery zone and finally the mode of transportation (Shipping rate calculator for e-Commerce Couriers). Additionally, products are even returned after usage for a certain number of days. Several estimates suggest that the online shoppers in India returned items worth between $\$ 800$ million to $\$ 1$ billion in the financial year 2014 - 15 (E-tailers change return policies in the bid to cut down losses, 2015). Now with the rapid growth of e-commerce industry, the issue of returns has become even more acute. This phenomenon seems to suggest that e-commerce firms need to develop a suitable RL network for collection, storage and disposition of the returned items which would optimize the total cost of RL and at the same time offer an acceptable level of responsiveness to the customers.

With this background, this present work attempts to address the following research questions:

- How many initial collection centers (ICCs) would be set up and where the same should be set up in a particular geographic location which would minimize the cost of RL? 
- There are numerous customer points from which returns emanate in a large city or in any other geographic location. At the same time there are a few ICCs in which returns are initially brought before being finally sent to the warehouses. The issue is which customer indexes would be assigned to which ICCs that would minimize the cost of RL.

- What should be the volume of items to be shipped from ICCs to the final warehouses in one trip which would minimize the cost of RL?

- How does varying the period of holding time at ICCs result in varying inventory carrying cost and transportation cost? What kind of insights can be obtained through the trade-offs between inventory carrying cost and transportation cost?

The remainder of the paper is organized as follows. The following section provides an overview of extant literature including both RL in traditional firms and e-commerce firms. Section 3 furnishes a snapshot of the e-commerce firm under the heading 'Case study'. Section 4 describes the model along with its assumptions, decision variables, parameters and constraints. Section 5 gives an overview of the data utilized in the model. Section 6 deals with data analyses and discussion including sensitivity analyses. Section 7 advances theoretical and managerial implications of the study findings. The paper ends with concluding remarks.

\section{LITERATURE REVIEW}

The concept of RL is being practiced by traditional organizations since more than last two decades. The same has recently been adopted by e-commerce firms. Accordingly, the review of the extant literature on RL is covered under two heads as discussed below.

\subsection{Reverse Logistics in Traditional Firms}

The existing literature is replete with many studies pertaining to the RL functions in traditional firms. Dowlatshahi (2000) provided a holistic view of RL considering both strategic and operational factors. Several researchers (Rogers and Tibben-Lembke, 2001; Toffel, 2004; Guide and Van Wassenhove, 2009; Lau and Wang, 2009) identified the motivation of organizations for pursuing RL functions. Rogers and Tibben-Lembke (2001) indicated in their findings that the competitive pressure is the dominant reason for most of the firms in taking back the returned goods. Toffel (2004) mentioned that reduction of production costs, promotion of an environmentally-friendly image, meeting customer needs, protecting after markets and preempting regulations induce an organization in undertaking RL activities. Guide and Van Wassenhove (2009) emphasized that the volume and quality of returns are the major drivers of RL functions. Lau and Wang (2009) indicated that fulfillment of obligation for environment protection and improvement of customer service are the two major drivers of a firm for pursuing RL functions.

Few other research findings (Rogers and TibbenLembke, 1999; Guide, 2000; Guide et al., 2000; 2006; Rogers et al., 2002; deBrito and Dekker, 2003; Blackburn et al.,2004; Savaskan et al., 2004; Toffel, 2004) revealed the types of return flow and their characteristics. Rogers and Tibben-Lembke (1999) classified the categories of returns as the items returned by supply chain partner (B2B) and the same returned by the final customer (B2C). Rogers et al. (2002) indicated how the returns of various types including consumer returns, marketing returns, asset returns, etc. should be managed across the whole reverse supply chain (RSC). deBrito and Dekker (2003) differentiated returns according to supply chain phases: manufacturing returns, distribution returns and customer returns. Guide (2000), Guide et al. (2000) and Toffel (2004) mentioned that the uncertainty in product returns, imbalances in return and demand rates and the unknown condition of returned products make the production planning and control of remanufacturing extremely complicated. Blackburn et al. (2004) demonstrated that there are broadly two categories of product returns: returns with high marginal value of time (MVT) and the returns with low MVT. They further suggested a decentralized and responsive RSC for high MVT products and centralized and efficient RSC for low MVT products. Guide et al. (2006) added that the companies facing large returns and high recoverable product value should adopt a responsive reverse network. Savaskan et al. (2004) considered three options for collection of used products from customers. They argued that the retailer happens to be the most effective agent for collection of returned products.

A significant number of research papers (Cruz-Rivera and Ertel, 2009; Mutha and Pokharel, 2009; Assavapopokee and Wongthatsanekorn, 2012) dealt with the network design of RL for collection and processing of EOL, EOU, unused and partially used items by utilizing mathematical programming approach. The issues concerned in the above studies include whether to open collection centers, recovery centers and disposal centers at suitable locations and also an appropriate volume of goods to be shipped from one facility to another with a view to realizing both economic and environmental objectives. Mokrini et al. (2019) carried out a study on the redesign of Moroccan public pharmaceutical supply chain in which it is found that the number of warehouses and their location depends on the distribution of demand and the type of road infrastructure. Ali and Nakade (2015) conducted a study on the location decision of distribution centers (DCs) and the shipment decision of products from suppliers to DCs and again from DCs to the customers in the event of supply chain disruption due to shortage of supply.

\subsection{Reverse Logistics in E-Commerce Firms}

The academic community has started showing interest on RL in e-commerce firms since last decade. Mukhopadhyay and Setoputro (2004) argued that a generous return policy would increase revenue but at the same time would increase cost due to increased likelihood of returns. They developed a profit maximization model to obtain optimal policies for price and the return policy. Ramanathan (2011) demonstrated through empirical analysis that handling of product returns plays an important role in shaping customer loyalty for both low-risk products and high-risk products but not for products that exhibit medium level of risk. We came across two studies (Pan et al., 2015; Chen et al., 2017) which have recommended crowdsourcing solution to collect city-wide e-commerce reverse flows. The solution tries to leverage the extra loading capacity and 
constant mobility of taxis to collect returned goods from customers and deliver the same to the retailers. In the crowdsourcing solution, the retailers have an incentive to outsource this task while taxi drivers have an opportunity to earn a little extra money by doing the above exercise. As mentioned in the Introduction section, few researchers (Yan et al., 2012; Liu, 2014; Zaarour et al., 2014) developed RL network design with reference to e-commerce firms for collection and disposition of returned items. The common elements evident in these papers is to determine the number and location of initial collection points and recycling/remanufacturing/3PL facilities/final return centers with a view to minimizing the total cost of RL operations. The above studies proposed generic models of RL network design in e-commerce firms and did not specifically account for the type, volume, frequency and size of the returns emanated from the final customers.

In real-life situations, it is quite essential to gather an idea about the profile and necessary statistics of returns while designing a RL network for e-commerce firms. The returns and cancellations of different categories of products are different as revealed in one of the reports in Indian Express. As per the report, category-wise cancellations and returns for fashion goods, FMCG, mobiles and large appliances fall in the range of $37-42 \%, 28-33 \%, 22-27 \%$, and $29-34 \%$ respectively (The Indian Express, April 6, 2018). The returns and cancellations were estimated based on gross merchandise value (GMV). It is also mentioned that the cancellations are mostly due to change of mind of the consumers which happens the most in case of fashion goods. Returns, on the other hand, are mainly due to incorrect product being delivered or the product being delivered is very different from the one ordered. Another report mentions that about $30 \%$ of all fashion products ordered online are returned by consumers due to various reasons (The Economic Times, January 17, 2018). Still another report reveals that apparel retailers started 2016 with a $30 \%$ return rate in which it is also mentioned that a third of all holiday purchases made online including clothing and shoes would be returned (Bold metrics blog, 2016). E-commerce Product Return Statistics and Trends (2016) further reveal that $92 \%$ of the respondents amongst prospective shoppers would purchase online again if the returns process is hassle-free. In addition, $79 \%$ of the shoppers want free return shipping and $67 \%$ of the shoppers check return page before making purchase decisions.

The above data pertaining to return types and return volume seem to suggest that fashion goods including apparels and footwear account for the highest percentage of returns in online retail followed by consumer electronics.

Accordingly, e-commerce firms should design an appropriate RL network keeping in mind the categories and volume of returns for proper collection and disposition of the same with a view to minimizing the total cost of $\mathrm{RL}$ operations. However, we did not come across relevant studies which have attempted to design RL network of ecommerce firms based on volume, frequency and characteristics of returned goods. The present study is an attempt to bridge the gap towards that direction.

\section{CASE STUDY}

The present study was carried out in an Indian ecommerce firm primarily engaged in retailing of fashion goods including both apparels and footwear across men, women and children, fashion accessories, lifestyle and personal care products, home furnishing etc. The firm initially operated on a B2B model for on-demand personalization of gift items. In 2011, the company shifted its focus on fashion and life-style products. The firm has a Pan-India presence and posted a turnover of INR 2000 crore in the fiscal year $2016-17$. However, we have confined the present study to the northern capital region (NCR) of Delhi. As regards its business model, the e-tailer follows both inventory-based model and marketplace-based model with the inventory-based model accounting for approximately $70 \%$ of the sales revenue while the remaining revenue is generated through marketplace-based model. Further inventory-based model followed by the firm has two variants: (1) Sale or Return (SOR) and (2) Outright purchase. SOR model accounts for approximately $20 \%$ of the revenue while outright purchase model generates the remaining sales of the total revenue emanated from inventory-based model. SOR model involves certain kind of contract agreement signed between the sellers and the e-commerce firm in which it is mentioned that the items purchased by the e-commerce firm would be stored in its warehouse and displayed in its site for sufficiently long period for sale. In case the items do not sell within this period, the same would be returned to the respective suppliers. Outright purchase model involves permanent transfer of ownership of the items through purchase by e-commerce firm. If the items purchased through this are not sold, the e-tailer has to assume the responsibility for liquidation of unsold inventories.

The e-commerce firm under study generates daily sales revenue ranging between INR 10 to 15 crores, i.e. an average daily sales revenue of INR 12.5 crores is generated by the firm on Pan-India basis. Delhi and NCR account for $6-8 \%$ of the total sales revenue, i.e. an average of $7 \%$ of total sales revenue is contributed by Delhi and NCR. The breadth of product range is very wide running into thousands of items. The price range of the products is also quite broad. For example, the price of the items varies from as low as INR 100/- for a handkerchief to as high as INR 1 lac for a sophisticated wrist-watch. The most frequent order size in terms of monetary value of the items occurs in the range of INR 1500.If we want to find out the approximate volume of items sold per day in Delhi and NCR, the same comes out to be 5833. Maximum return experienced by the firm occurs in case of apparels and foot wears which falls in the range of 25 $-30 \%$. If we consider an average of $27.5 \%$

return, then the volume of returns comes out to be approximately 1600 per day. The total space required for returned items in the ICCs is computed based on an estimate with regard to the number of units handled by Filpkart in its fulfillment centre. Flipkart's largest fulfillment centre has a size of 2.2 lakh square feet and it can handle 1.2 lakh units per day (The Economic Times, October 5, 2015). Considering daily return volume of 1600 , the maximum holding period of returns in the initial collection centers (ICCs)to be 4 days and 3\% increase in future returns, the approximate total area required for returned items in the 
ICCs of Delhi and NCR comes out to be 12,000 square feet. If initially the number of ICCs is considered to be 4 , the average area required for each ICC would be 3000 square feet.

The return policy of the firm stipulates the terms and conditions and also the maximum number of days within which the purchased item/s could be returned. Of course, not all items are eligible for return. The return process involves arrival of the Delivery Person to the designated place based on the pick-up request made by the customer and subsequently preliminary checking of quality of returned goods performed by the person in front of the customer. If the returned item passes the preliminary quality check, the same is picked up by the person for onward delivery to the nearest distribution centre. These distribution centers act as intermediate storage centers for both customer-ordered and returned items. These are also known as ICCs. The returned items undergo further quality inspections in the ICCs. If the returned items pass these quality tests, the refund for the returns is processed and sent to the customers. Currently the e-commerce firm has as many as four ICCs in the northern capital region (NCR) of Delhi. The returned items are subsequently sent to the main warehouse based in NCR in most of the cases. Based on the condition of the items, the same is either put up in e-commerce platform or liquidated depending on whether the items have emanated from inventory of the firm. If the returned item is sourced through market place-based model, the same is sent back to the concerned suppliers/sellers.

\section{MODEL}

We have developed a mixed integer linear programming (MILP) model to capture different facets of the problem of reverse logistics in e-commerce.

\subsection{Assumptions}

- A number of large neighborhoods in the NCR of Delhi from which returns emanate have been considered as customer indexes.

- The number of ICCs and their location in the study region have been identified in advance. The ICCs have reasonable capacity to hold the daily returns for a few days.

- The returns emanated from one customer index are allocated to only one ICC, i.e. one customer index will be assigned to only one ICC. Multiple customer indexes can have their returns allocated to one ICC.

- The annual rental and maintenance costs of ICCs have been estimated based on the prevailing cost figures of the study region.

- The warehouses in which the returned items are finally sent are identified in advance.

- The transportation cost from customer indexes to the ICCs and again from ICCs to the warehouses have been estimated based on the cost figures available from the secondary sources.

- A multiplication factor has been introduced to account for the variability in transportation cost depending on whether the items are moved in less than truck-load
(LTL) mode or in full truck-load (FTL) mode. When the holding period of the items in ICCs increases, the items are likely to be moved in FTL mode from ICCs to final warehouses. Accordingly unit cost of transportation tends to show a diminishing trend. On the contrary, when the holding period at ICCs decreases, the items would be moved in LTL mode. This leads to an increase in unit transportation cost of returned items. Multiplication factor attempts to capture this phenomenon of varying unit cost of transportation due to varying holding period of returned items in ICCs.

- Since the study is confined to the NCR, $80 \%$ of the returns are assumed to be sent to the final warehouse located in Gurugram (the northern region). The remaining $20 \%$ of returns are equally divided between Mumbai and Bangalore warehouse. This is finalized in consultation with the professionals based in the above e-commerce firm.

\subsection{Sets}

I: Set of customer indexes, $i \in I$

J: Set of initial collection centers, $j \in J$

$K$ : Set of final warehouses, $k \in K$

\subsection{Parameters}

$C_{j} \quad=$ Annual cost of renting and maintaining $j^{t h}$ initial collection centre (ICC)

$V_{i} \quad=$ Volume of items returned by customer index $i$ per day

$T \quad=$ Total number of annual working days

$t=$ Holding time of returned item in an ICC

$h \quad=$ Inventory carrying cost per unit of returned item on daily basis

$u_{i j} \quad=$ Unit transportation cost of returned item from customer index $i$ to $\mathrm{ICC} j$

$u_{j k}=$ Unit transportation cost of returned item from ICC $j$ to the final warehouse $k$

$f \quad=$ A multiplication factor which takes care of the variability of transportation cost depending on whether the items are moved in full truck load (FTL) or less-than truck load (LTL) mode.

$M \quad=$ A big number

$g \quad=$ Percentage of returned items

$P \quad=$ Maximum number of returned items that could be accommodated in an ICC in case it is selected

$Q \quad=$ Minimum number of returned items that need to be kept in an ICC in case it is selected 


\subsection{Decision Variables}

$Y_{j}=\left\{\begin{array}{l}1, \text { if an ICC is set up at } \mathrm{j} \\ 0, \text { otherwise }\end{array}\right.$

$A_{i j}=\left\{\begin{array}{l}1, \text { if customer index } \mathrm{i} \text { is allocated to ICC } \mathrm{j} \\ 0, \text { otherwise }\end{array}\right.$

$X_{j k}=$ Volume of items returned from ICC $j$ to final warehouse $k$ in one trip

\subsection{Formulation}

\section{Minimize $\mathrm{Z}=$}

\section{Subject to}

$$
\sum_{j} C_{j} Y_{j}+h T\left(\frac{t+1}{2}\right) \sum_{i} \sum_{j} V_{i} A_{i j}+T \sum_{i} \sum_{j} V_{i} u_{i j} A_{i j}+f \frac{T}{t} \sum_{j} \sum_{k} u_{j k} X_{j k}
$$

$$
\begin{array}{ll}
\sum_{j} A_{i j}=1 & \forall i \\
\sum_{i} A_{i j} \leq M Y_{j} & \forall j \\
g t \sum_{i} V_{i} A_{i j}=X_{j k} & \forall j \\
t \sum_{i} V_{i} A_{i j} \leq P Y_{j} & \forall j \\
t \sum_{i} V_{i} A_{i j} \geq Q Y_{j} & \\
\sum_{j} Y_{j}=4 & \\
A_{i j}=0 \text { or } 1 & \\
Y_{j}=0 \text { or } 1 & \\
X_{j k} \geq 0 &
\end{array}
$$

The elements of reverse logistics cost shown in the objective function are as follows: The first element indicates the annual cost of rental and maintenance for returned items, the second element denotes the inventory carrying cost of returned items at ICCs and the third element shows the annual transportation cost of returned items from customer indexes to ICCs. Finally the last element includes the transportation cost from ICCs to final warehouses. The present problem considers three designated final warehouses, each one being located in Gurugram, Bangalore and Mumbai. As such the last component of transportation cost was further split into three

sub-components of transportation cost while trying to find out solution through optimization software.

Constraint (1) ensures that a customer index is allocated to a single ICC. Each customer index represents a combination of customers located around a particular neighborhood. Constraint (2) averts chances of any returned items from customers to be gathered at a closed ICC by multiplying the right side of the equation by $\mathrm{M}$ (a big number). Constraint (3) indicates the balance of flow of returned items at ICCs, i.e. between the incoming flow from customer indexes to ICCs and outgoing flow from ICCs to final warehouses. While finding out solution, constraint (3) was further split into three constraints. One of the constraints specifies that $80 \%$ of the returned items coming into ICCs would go to warehouse located in Gurugram. The remaining two constraints specify that each warehouse located in Bangalore and Mumbai would receive $10 \%$ of the returned items. Constraint (4) shows the maximum number of returned items that could be accommodated in an ICC, if it is selected. Constraint (5) shows the minimum number of returned items that should be kept in an ICC (in case it is selected) in order to indicate a reasonable level of utilization of the same. Constraint (6) makes sure that four ICCs are selected. Constraint (7) sets the decision variables relating to allocation of customers to ICCs as binary. Constraint (8) sets the decision variables of the establishment of ICCs as binary. Finally constraint (9) reveals that the decision variables pertaining to the number of returned items from ICCs to the final warehouses are non-negative. 


\section{DATA}

For finding out optimum solution to the above problem, we estimated real-life data on all parameters based on collecting information from secondary sources, consulting concerned professionals in online retail industry and finally exercising our own judgment. This is shown in Appendix A through Appendix F. Appendix $\mathbf{A}$ indicates annual rental and maintenance costs of ICCs $\left(\mathrm{C}_{\mathrm{j}}\right)$ for varying number of ICCs along with the basis of computation of costs at different regions of Delhi and NCR. The data reveals that when the number of ICCs is increased, the requirement in terms of the size of individual ICCs decreases. This renders the per square rental fee of ICCs a little more expensive. The opposite is true, when the number of ICCs is decreased. The rental and maintenance cost in the candidate locations has been estimated based on consultation with the real estate agents based in Delhi. Appendix B contains the volume of items returned daily $\left(\mathrm{V}_{\mathrm{i}}\right)$ by customer indexes. Appendix $\mathbf{C}$ includes the number of operating days in a year (T), average holding time of returned items in an ICC (t) and inventory carrying cost per unit per day (h). Appendix D shows the unit transportation cost from customer indexes to ICCs $\left(\mathrm{u}_{\mathrm{ij}}\right)$ while Appendix $\mathbf{E}$ presents unit transportation cost from ICCs to final warehouses $\left(\mathrm{u}_{\mathrm{jk}}\right)$. Appendix $\mathbf{F}$ shows the multiplication factor(f) of transportation cost due to the variation in holding time of returned items in the ICCs. The values of the factor for different holding periods have been finalized after extensive trial runs. The purpose of the trial runs was to examine whether this reflects real-life scenario with specific reference to varying transportation cost due to the items being moved in FTL or LTL mode emanating from varying holding periods in ICCs. Finally Appendix G.1 through $\mathrm{G} .5$ presents the values of $\mathrm{P}$ and $\mathrm{Q}$ indicating respectively the maximum number of returned items that could be accommodated in an ICC and the minimum number of items that should be kept in an ICC, in case it is selected under different situations. The value of $\mathrm{P}$ in the base model is determined considering the incoming daily volume of returns, the holding time at ICC, the number of ICCs and a cushion in capacity considering certain growth in returns. The value of $\mathrm{Q}$ is computed as $40 \%$ of the value of $\mathrm{P}$ in order to have a minimum level of utilization of an ICC. The optimization model consists of 144 decision variables, out of which 18 are linear variables and the remaining 126 are binary variables. In addition, the model has a total of 58 constraints.

\section{DATA ANALYSIS AND DISCUSSION}

LINGO 14.0 software was utilized for finding out optimum solution to the above problem. The optimum cost of RL turns out to be INR 6,36,96,460 per annum. The output of the model gives rise to several meaningful insights. First, the model selects four ICCs each one being located in central Delhi, south Delhi, west Delhi and Gurugram out of six ICCs spread over the NCR of Delhi. Second, the model allocates each customer index to a particular ICC. Third, it computes an appropriate volume of returned items to be shipped from ICCs to all three warehouses per trip. In addition, the results also reveal that the component of transportation cost from ICCs to the warehouses is the highest amongst all other components of RL cost. The components of inventory carrying cost and annual rental and maintenance cost of ICCs are quite low compared to the component of transportation cost from ICCs to the warehouses. Even the transportation cost from customer indexes to ICCs is also quite high. We have individually computed all elements of RL cost which is shown in Exhibit 1. The exhibit reveals that the inventory carrying cost of the returned items accounts for a meagre $3.4 \%$ of the total cost of RL in the present e-commerce firm and the rental and maintenance cost of ICCs constitutes only $4.97 \%$ of the total cost. Bulk of the cost of RL is accounted for by the transportation cost of the returned items. $27.4 \%$ of the total cost covers the cost of transportation from customer indexes to ICCs and the remaining $64.19 \%$ of the total cost makes up the cost of transportation from ICCs to the final warehouses. This is consistent with the findings of Zaarour et al. (2014). This revelation provides important insights to the managers in terms of the contribution of elemental costs of RL towards total cost of RL in the e-commerce firm and enables them in devising suitable strategies to improve the efficiency of reverse logistics operations of the e-commerce firm.

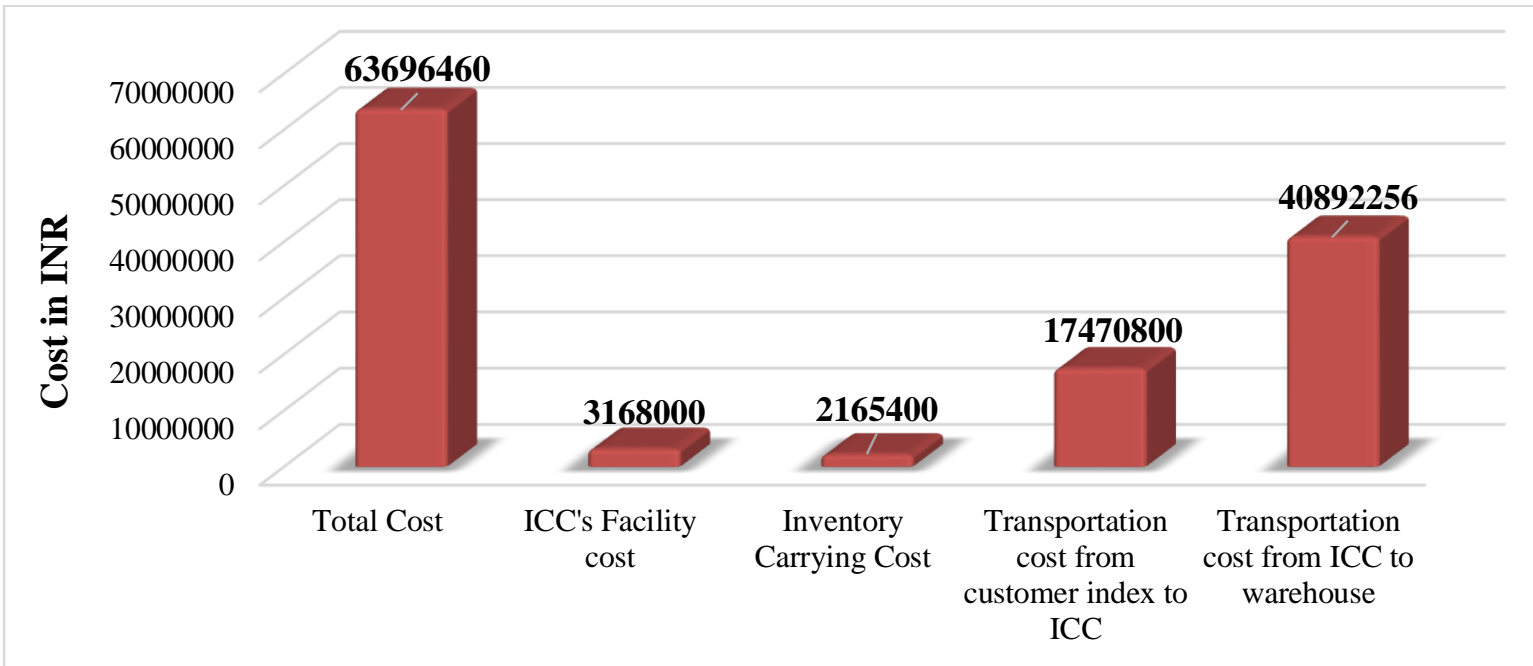

Individual elements of Reverse Logistics cost for the E-commerce Firm

Exhibit 1. Elemental costs of reverse logistics in the e-commerce firm under study 


\subsection{Sensitivity Analysis}

The sensitivity of the MILP model was tested by varying the values of the most important parameters with a view to understanding the behavior of the model with respect to changes in these parameter values. The parameters include the daily volume of returned items, holding time of returned items in the ICCs, transportation cost with and without freight discount with increase in returns and the number of ICCs.

\subsubsection{Impact of Variation in Returns Volume $\left(V_{i}\right)$}

We have considered the data provided in Appendix B utilized in the original model as the base value of returns volume $\left(\mathrm{V}_{\mathrm{i}}\right)$. We have varied the value of $\mathrm{V}_{\mathrm{i}}$ by $5 \%, 10 \%$, $15 \%$ and $20 \%$ from the base value in both directions and have utilized the data of $\mathrm{P}$ and Q provided in Appendix G.2 to find out solution in each case. We have individually computed inventory carrying cost, facilities rental and maintenance cost of ICCs, transportation cost from customer indexes to ICCs and also transportation cost from ICCs to warehouses. The total cost of RL is also computed under each scenario. This is shown in Exhibit 2. The exhibit reveals that inventory carrying cost, transportation cost from customer indexes to ICCs and the transportation cost from ICCs to warehouses increase gradually with the increase in the volume of returns. However, the facilities rental and maintenance cost remains the same with increase or decrease of the returns volume. We further investigated the impact of change in $\mathrm{V}_{\mathrm{i}}$ on the selection of ICCs which is shown in Exhibit 3. When $V_{i}$ is varied in both directions, we do not observe any change in the selection of ICCs from the base model.

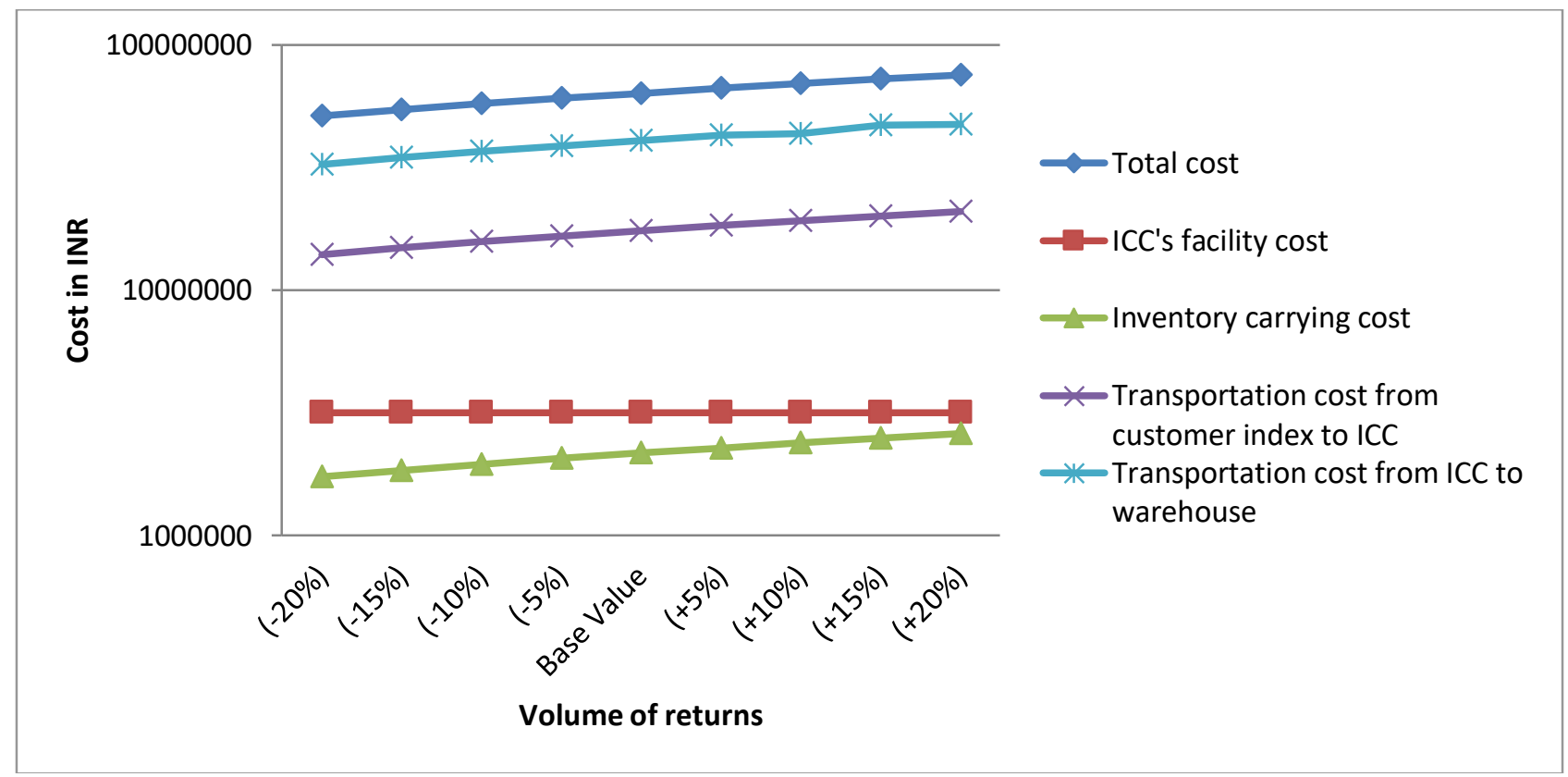

Exhibit 2. Impact of variation in returns volume on elemental cost of reverse logistics

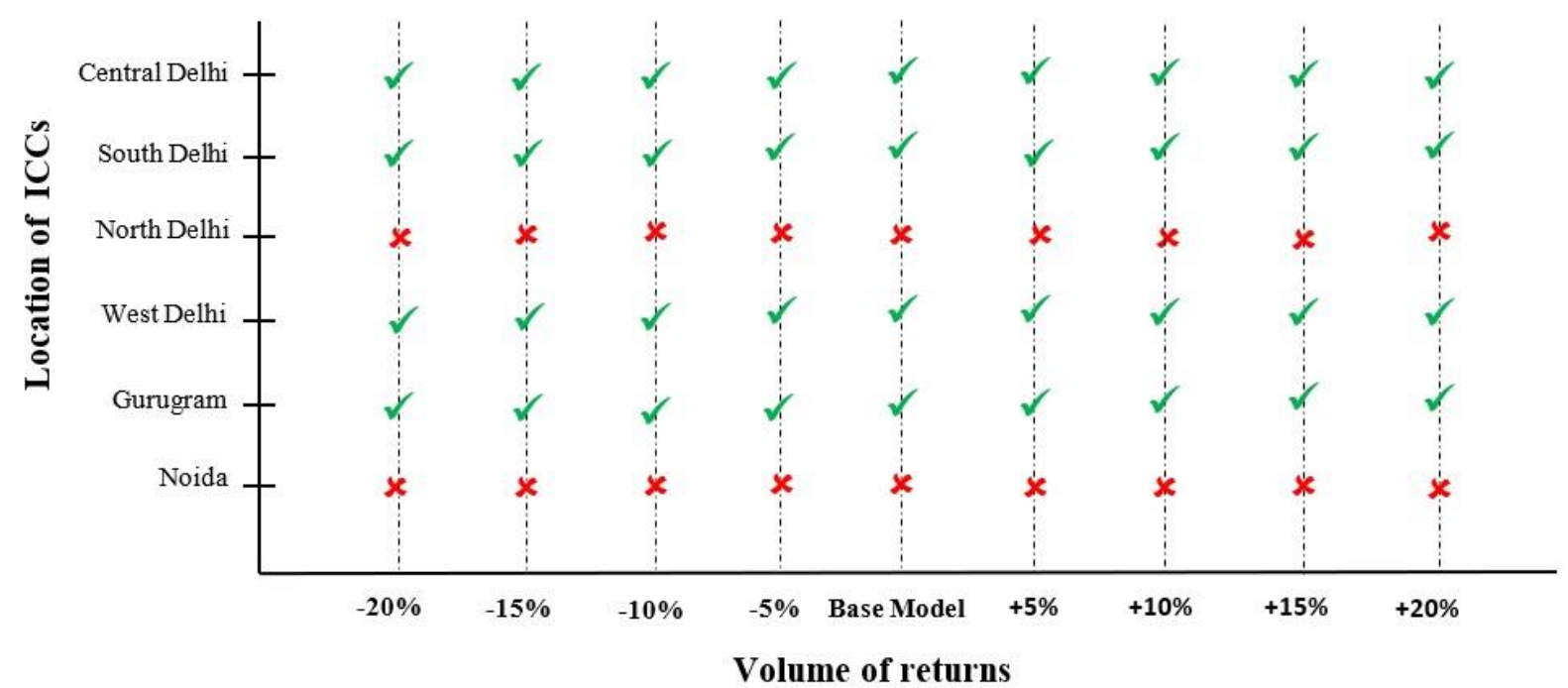

Exhibit 3. Impact of variation in returns volume on the selection of ICCs 


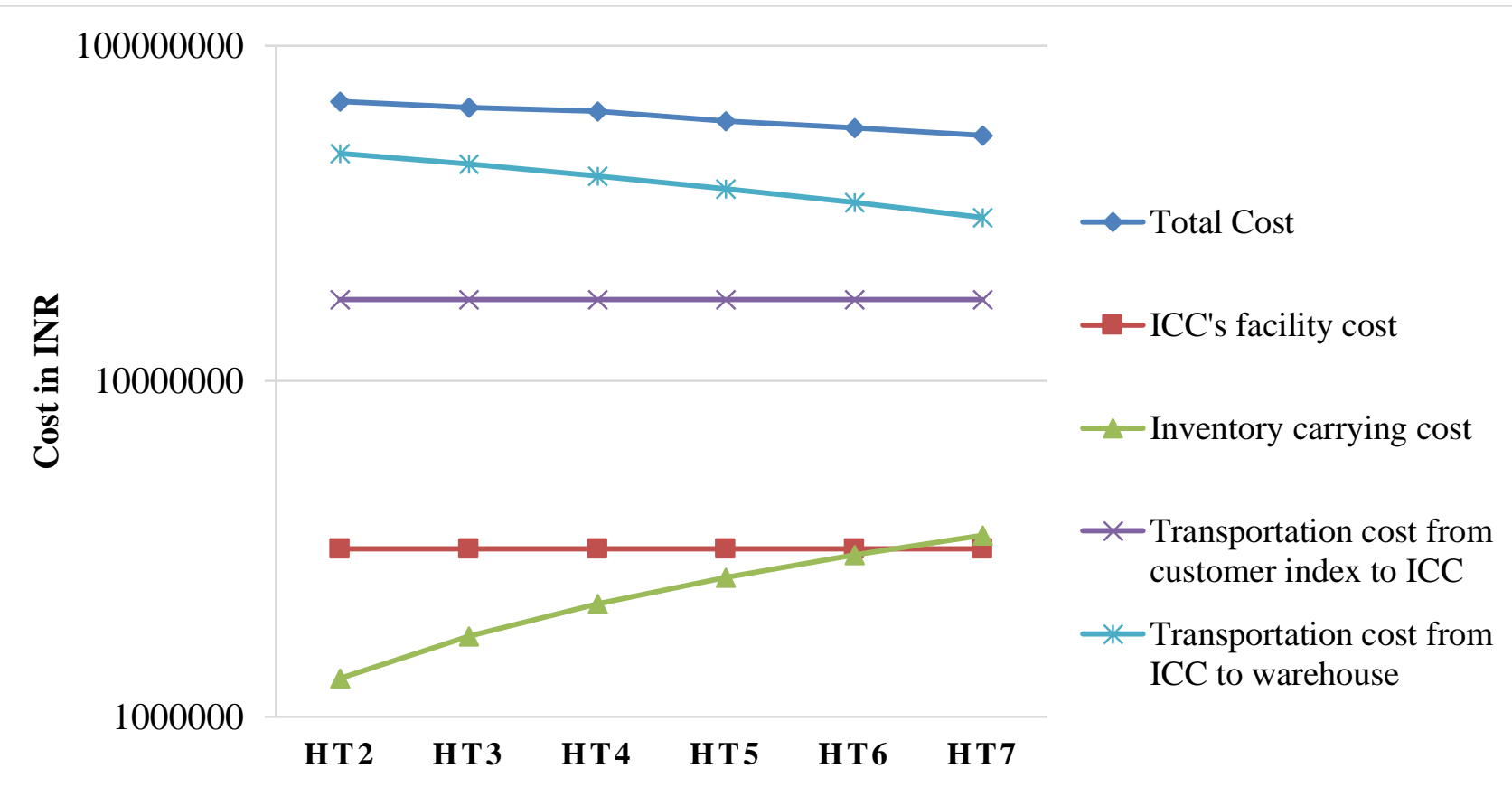

Holding time in days

Exhibit 4. Impact of variation in holding time at ICCs on elemental cost of reverse logistics

6.1.2 Impact of variation in holding time $(t)$ of returns at ICCs

The data provided in Appendix $\mathbf{C}$ in respect of holding time $(\mathrm{t})$ of returned items at ICCs is considered the base value of holding time. We have varied the values of ' $t$ ' at ICCs from 4 days by 1 day each in both directions and have utilized the data of $\mathrm{P}$ and $\mathrm{Q}$ provided in G.3 to determine solution in each case. We have computed inventory carrying cost, facilities rental and maintenance cost of ICCs, transportation cost from customer indexes to ICCs and also transportation cost from ICCs to warehouses individually for each case. The analyses have been made considering holding time at ICCs to be 2 days, 3 days, 5 days, 6 days and 7 days. The total cost of RL is also computed under each scenario. This is shown in Exhibit 4.

The exhibit reveals that inventory carrying cost of returns increases with increase in holding time of returns at ICCs. On the contrary, the transportation cost of returns from ICCs to warehouses decreases with increase in holding time of returns at ICCs. This phenomenon demonstrates similar kind of pattern observed in respect of inventory carrying cost and transportation cost in forward logistics (Chopra, and Kalra, 2019; Simchi-Levi et al., 2008). The behavior of these two elements of cost provides valuable insights to the managers in respect of achieving cost-responsiveness tradeoff. The other elements of cost including facilities maintenance cost of ICCs and transportation cost of returns from customers indexes to ICCs do not vary much with increase or decrease in holding time of returns at ICCs.
We have further investigated the impact of change in ' $t$ ' on the selection of ICCs. When ' $t$ ' is varied in both directions, we again do not observe any change in the selection of ICCs from the base model. The change in the behavior of the model due to change in ' $t$ ' exactly resembles the same as demonstrated in Exhibit 3.

\subsubsection{Impact of increase in returns volume with and without freight discount}

We have considered the base value of returns provided in Appendix B and visualized a scenario of increase in returns to the tune of $10 \%, 20 \%, 30 \%, 40 \%$ and $50 \%$ with a corresponding freight discount of $2 \%, 4 \%, 6 \%, 8 \%$ and $10 \%$ respectively in the unit transportation cost of returns from ICCs to warehouses. The rationale behind providing higher rate of discount in higher volume of returns is to motivate the online retailer to take advantage of economies of scale in transportation. We have demonstrated this analysis with 2days holding period. The idea behind doing this exercise is to identify the most attractive region of freight discount which would provide the online retailer the least total cost. We have further compared this total cost with the total cost obtained without freight discount. This is demonstrated in Exhibit 5. The Exhibit 5 shows that the total cost of RL for the e-commerce firm with freight discount is obviously less than the total cost without freight discount for almost all ranges of freight discount with increasing volume of returns. 


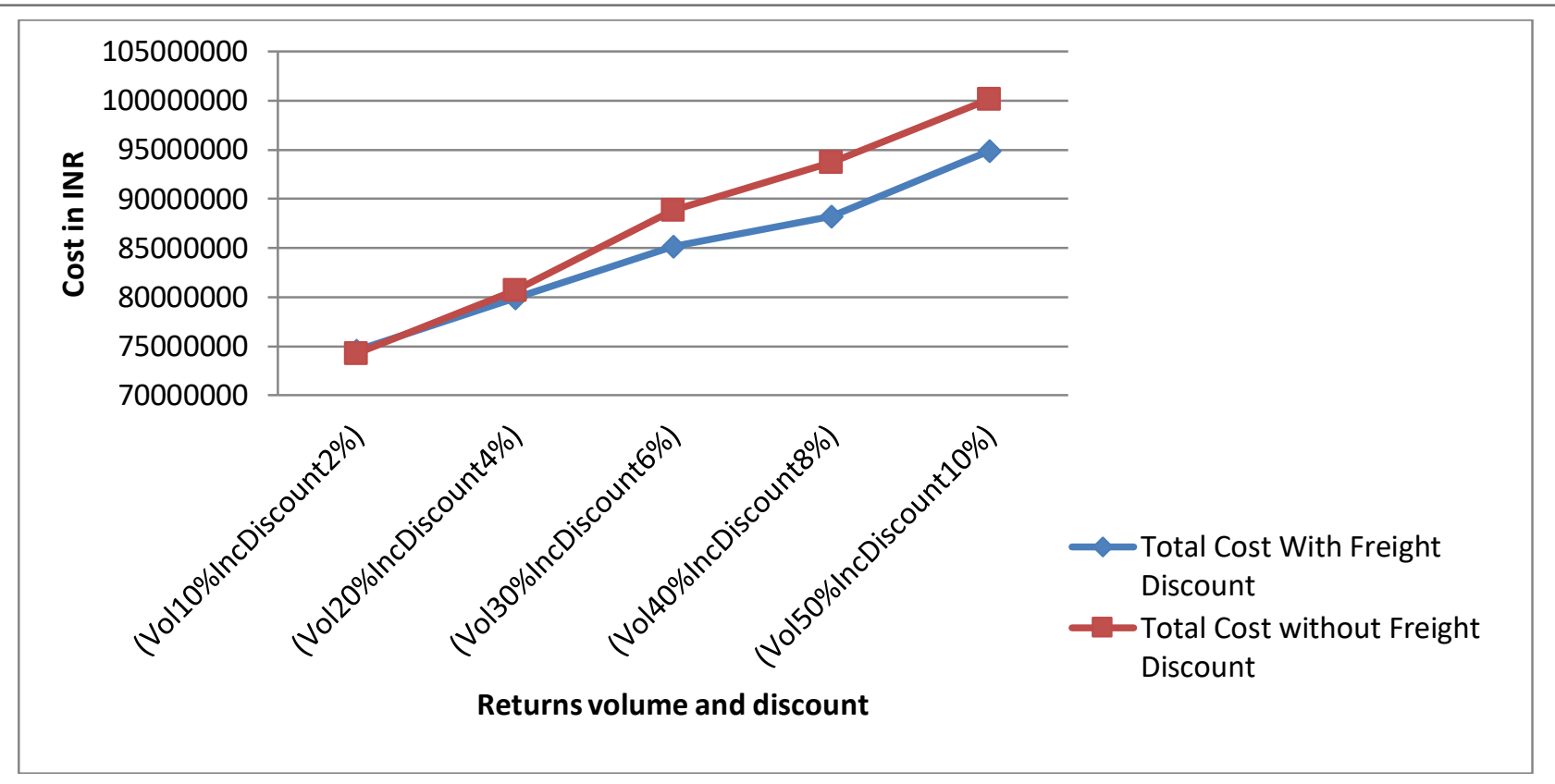

Exhibit 5. Impact of increase in returns volume with and without freight discount on total cost (for 2-days holding period)

However, the maximum impact of freight discount in terms of reduced total cost is observed in the range of $40 \%$ increase in returns volume with $8 \%$ freight discount. This is clearly indicated in Exhibit 5.

The same exercise has been repeated with 3-days, 4days, 5-days and 6-days holding period. We have observed that in all four cases the total cost with freight discount is less than the total cost without freight discount for all ranges of freight discount with increasing volume of returns. The reduction in total cost with freight discount in the above four cases is identical to the same as observed in Exhibit 5. In addition, all four cases demonstrate almost similar kind of behavior in respect of maximum impact of freight discount. The attractive region in terms of reduced total cost falls in the range of $8 \%$ freight discount with $40 \%$ increase in returns volume. We have utilized the data of $\mathrm{P}$ and $\mathrm{Q}$ provided in Appendix G.4 for doing the above exercise.

In addition, we have also compared the total cost of RL with freight discount considering 2-days holding period, 3days holding period, 4-days holding period, 5-days holding period and 6-days holding period. This is shown in Exhibit 6.

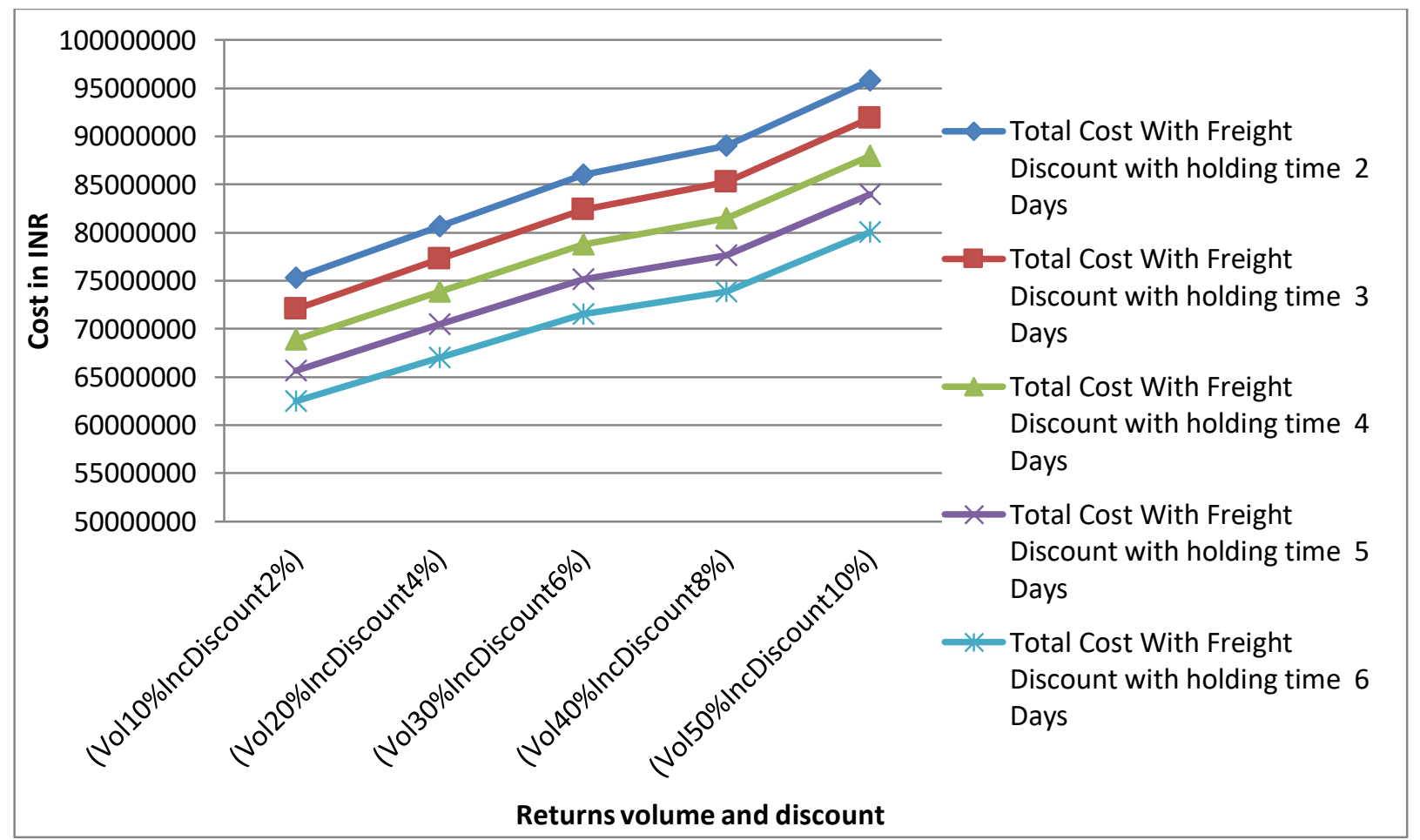

Exhibit 6. Impact of increase in returns volume with freight discount on total cost considering 2-days, 3-days, 4-days, 5-days, 6-days holding period 
The above exhibit indicates that the total cost with freight discount gradually decreases with increase in the holding time of returned items in the ICCs. This revelation further demonstrates the cost-responsiveness trade-off between parcel mode of transportation and the batch mode of transportation. Parcel mode of transportation implies movement of returns in smaller volume with higher frequency of movement which provides improved responsiveness with high cost. On the contrary, the batch mode of transportation indicates the movement of returns in higher volume with reduced frequency of movement which provides improved efficiency of RL but reduced responsiveness.

\subsubsection{Impact of variation in the number of ICCs}

The number of ICCs considered in the original model was four, which is taken to be the base value. We have varied the number of ICCs by one and two in both directions and have utilized the data $\mathrm{P}$ and $\mathrm{Q}$ provided in $\mathrm{G} .5$ to determine solution in each case. We have individually computed inventory carrying cost, facilities rental and maintenance cost of ICCs, transportation cost from customer indexes to ICCs and also transportation cost from ICCs to warehouses. This is shown in Exhibit 7.The exhibit shows that the facilities rental and maintenance cost of ICCs gradually increases with increase in the number of ICCs while the transportation cost from customer indexes to ICCs gradually decreases. This phenomenon indicates that the increase in facilities cost is offset by the decrease in transportation cost which is supported in extant literature particularly in terms of forward logistics (Chopra and Kalra, 2019; Simchi-Levi et al., 2008). The other elements of cost including inventory carrying cost and transportation cost from ICCs to final warehouses more or less remain the same. In addition, we observe hardly any change in the total cost of reverse logistics with respect to variation in the number of ICCs. We further investigated the impact of change in the number of ICCs on the selection of ICCs which is shown in Exhibit 8. When the number of ICC is varied in both directions, we observe changes in the selection of ICCs from the base model, which is suitably captured in Exhibit 8.

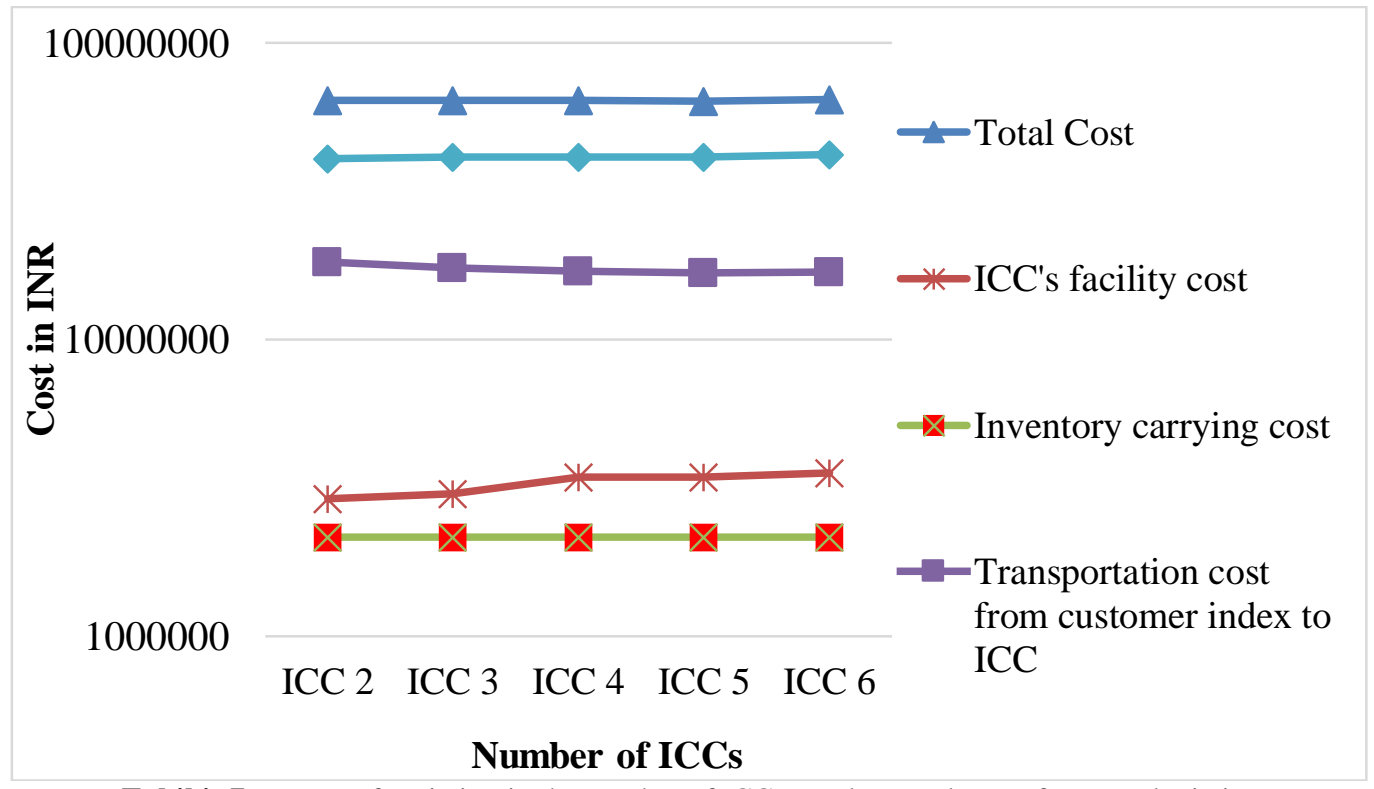

Exhibit 7. Impact of variation in the number of ICCs on elemental cost of reverse logistics

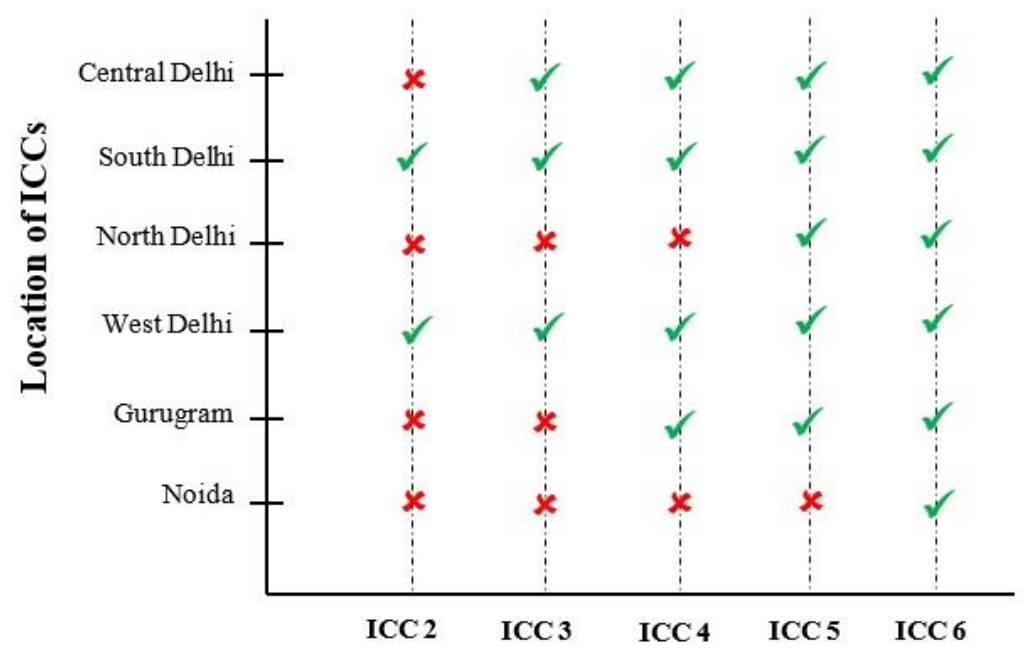

Number of initial collection centres

Exhibit 8. Impact of variation in the number of ICCs on the selection of ICCs 


\section{THEORETICAL AND MANAGERIAL IMPLICATIONS}

The findings of the above empirical case study provide several interesting insights for both academics and practitioners in the context of RL operations in e-commerce firms. First, the elemental costs of RL reveal that the components of inventory carrying cost and facilities cost are extremely low compared to the two components of transportation cost. The bulk of the costs is accounted for by the cost for bringing the returns from customer points to the ICCs and again from the ICCs to the final warehouses. There seems to be two possible reasons for this very high cost of transportation in RL operations of e-commerce firms. The returns purchased through SOR need to be sent to the suppliers fast in order to enable them to sell the same through alternative channels which would allow the e-commerce firm to avoid making costly payment to the suppliers on goods initially sold and subsequently returned. Further the returns occurred due to outright purchase need to be sent to the warehouse quickly in order to avoid obsolescence of the same and enable the e-commerce firm to realize their salvage value. This observation is markedly different from the trend observed in forward logistics and is somewhat counterintuitive.

Second, with the increase in returns volume, all elements of RL costs gradually increases while the element of facilities cost remains the same. This probably indicates that the existing capacity of ICCs is somewhat higher compared to the returns volume due to which the cost of this element has not increased. Third, when the holding period of returns at ICCs is increased, inventory carrying cost gradually increases and simultaneously the transportation cost from the ICCs to the final warehouses decreases. This finding replicates the trend observed in forward logistics and reinforces the theory of cost-responsiveness trade-offs between inventory carrying cost and transportation cost of forward logistics in reverse logistics. Fourth, the step-wise increase in freight discount with step-wise increase in returns volume reveals that the behavior of total cost curve with freight discount is not uniform across all returns volume and the corresponding freight discount. At some point, the total cost curve exhibits a steep decrease. Probably the constituent elements of RL costs at different break-points behave differently. This seems to be a unique revelation of the study findings. Further, the nature of the total cost curves for different holding periods demonstrates almost identical trend. When the holding period at ICCs increases, the total cost with freight discount decreases. Fifth, when the number of ICCs increases, the facilities cost gradually increases and the transportation cost from customer indexes to ICCs gradually decreases. This observation reflects the similar kind of behavior observed in respect of facilities cost and transportation cost in forward logistics and thus supports the same relationship between the above two costs in reverse logistics. The above revelations seem to make a significant contribution to the existing body of logistics literature.

The managers involved in dealing with RL operations in e-commerce firms derive several meaningful insights. First, the clear estimate of different elements of RL cost allows the managers to further investigate the reasons of disproportionately higher component of transportation cost and thus enables them to explore ways and means to improve the efficiency of transportation in RL. Second, managers can roughly estimate the cost incurred on maximum capacity of the ICCs beyond which the same would show an increasing trend. Thus, they can recommend an appropriate capacity of ICCs based on returns volume. Third, the managers can have a clear idea as to where the ICCs should be located based on the results of sensitivity analyses of the volume of returns, holding time and the number of ICCs. Fourth, the costresponsiveness trade-offs occurred due to varying holding periods in the ICCs provides managers a clear idea about the behavior of inventory carrying cost and transportation cost and thus enables them to select a suitable holding period of returns in the ICCs. Fifth, the step-wise increase in freight discount with step-wise increase in returns volume provides a very important insight to the managers in terms of identifying the most attractive zone of total cost of RL. The managers can thus recommend suitable freight discounts for different volumes of returns with a view to obtaining a substantial reduction in the total cost of RL. Simultaneously the managers can do the same experiment with different holding periods and finally decide a particular holding period and an appropriate freight discount for a particular volume of return. Finally, the relationship between facilities cost, transportation cost and the total cost of RL gives an idea to the mangers as to how many ICCs need to be maintained with a view to achieving efficiency and an appropriate level of responsiveness in RL.

\section{CONCLUDING REMARKS}

The present study has attempted to develop a RL network design for an online fashion retailer by collecting relevant data from secondary sources and also by consulting experienced professionals involved in online retailing of the above firm. As mentioned earlier, the volume of returns including both apparels and footwear is quite high for an ecommerce firm, which has a direct impact on its bottom line. Thus, the primary motivation of this work was to minimize the total cost of RL operations spanning across collection, inspection, storage and disposition of returns. The decision variables include the number and the location of initial collection centers (ICCs) for collection of returns, the assignment of customer indexes to the appropriate ICCs and the volume of returns to be sent to the final warehouse in one shipment. The findings provide several meaningful insights to both the academics and the practitioners. Similar kind of study could also be replicated in an e-commerce firm engaged in consumer electronics and the related items and also in a generic e-commerce firm engaged in retailing of wide range of items with suitable modifications.

The study is not free from limitations. First, the RL network design proposed in this study is based on only one broad category of products including fashion goods, lifestyle products, personal care products etc. Second, the study was confined to only one particular geographic location. Third, the behavior of daily returns is assumed to be deterministic whereas the very nature of returns is unpredictable and uncertain in nature. Fourth, while developing the RL network design for an e-commerce firm, the study did not attempt to study the dynamics of its forward 
logistics designed to deliver the goods from warehouses to customers' doorsteps.

Future study should attempt to develop a RL network design which is probably suitable for a broad category of items. Lessons from the experiences of e-commerce firms in respect of returns behavior from other countries including China and the US should be learnt in order to gather an idea about the future trend of returns for developing a RL network design. Future study should endeavor to capture uncertainty inherent in returns and accordingly develop a stochastic RL network design for an e-commerce firm. Finally, the future study should attempt to develop an integrated network integrating both forward and reverse logistics for an ecommerce firm with a view to optimizing the total supply chain cost and at the same time providing an acceptable level of responsiveness to the customers.

\section{APPENDICES}

Appendix A: Annual rental and maintenance cost of ICCs

\begin{tabular}{|c|c|c|c|}
\hline $\begin{array}{c}\text { Number of ICCs \& size of } \\
\text { each ICC }\end{array}$ & Location of ICC & $\begin{array}{c}\text { Monthly rental fee per square } \\
\text { feet (INR) }\end{array}$ & $\begin{array}{c}\text { Annual rental and maintenance } \\
\text { cost (INR) }\end{array}$ \\
\hline \multirow[b]{2}{*}{ Number: 4 (Base Model) } & $Y_{1}$ (Central Delhi) & 23 & $C_{1}=828000$ \\
\hline & $Y_{2}$ (South Delhi) & 22 & $\mathrm{C}_{2}=792000$ \\
\hline \multirow{4}{*}{ Size: 3000 square feet } & $\mathrm{Y}_{3}$ (North Delhi) & 21 & $C_{3}=756000$ \\
\hline & $\mathrm{Y}_{4}$ (West Delhi) & 21 & $\mathrm{C}_{4}=756000$ \\
\hline & $\mathrm{Y}_{5}$ (Gurugram) & 22 & $C_{5}=792000$ \\
\hline & $\mathrm{Y}_{6}$ (Noida) & 20 & $C_{6}=720000$ \\
\hline \multirow{3}{*}{ Number: 3} & $\mathrm{Y}_{1}$ (Central Delhi) & 22 & $C_{1}=1056,000$ \\
\hline & $\mathrm{Y}_{2}$ (South Delhi) & 21 & $\mathrm{C}_{2}=1008,000$ \\
\hline & $\mathrm{Y}_{3}$ (North Delhi) & 20 & $C_{3}=960,000$ \\
\hline \multirow[t]{3}{*}{ Size: 4000 square feet } & $\mathrm{Y}_{4}$ (West Delhi) & 20 & $C_{4}=960,000$ \\
\hline & $\mathrm{Y}_{5}$ (Gurugram) & 21 & $C_{5}=1008,000$ \\
\hline & $\mathrm{Y}_{6}$ (Noida) & 19 & $C_{6}=912,000$ \\
\hline \multirow[b]{2}{*}{ Number: 2} & $\mathrm{Y}_{1}$ (Central Delhi) & 22 & $\mathrm{C}_{1}=1557,600$ \\
\hline & $\mathrm{Y}_{2}$ (South Delhi) & 21 & $\mathrm{C}_{2}=1486,800$ \\
\hline \multirow{4}{*}{ Size: 5900 square feet } & $\mathrm{Y}_{3}$ (North Delhi) & 20 & $C_{3}=1416,000$ \\
\hline & $\mathrm{Y}_{4}$ (West Delhi) & 20 & $C_{4}=1416,000$ \\
\hline & $Y_{5}$ (Gurugram) & 21 & $C_{5}=1486,800$ \\
\hline & $Y_{6}$ (Noida) & 19 & $\mathrm{C}_{6}=1345,200$ \\
\hline \multirow{3}{*}{ Number: 5} & $Y_{1}$ (Central Delhi) & 24 & $C_{1}=725,760$ \\
\hline & $\mathrm{Y}_{2}$ (South Delhi) & 23 & $\mathrm{C}_{2}=695,520$ \\
\hline & $Y_{3}$ (North Delhi) & 22 & $C_{3}=665,280$ \\
\hline \multirow[t]{3}{*}{ Size: 2520 square feet } & $\mathrm{Y}_{4}$ (West Delhi) & 22 & $C_{4}=665,280$ \\
\hline & $Y_{5}$ (Gurugram) & 23 & $C_{5}=695,520$ \\
\hline & $\mathrm{Y}_{6}$ (Noida) & 21 & $C_{6}=635,040$ \\
\hline \multirow{6}{*}{ Size: 2200 square feet } & $Y_{1}$ (Central Delhi) & 24 & $C_{1}=633,600$ \\
\hline & $Y_{2}$ (South Delhi) & 23 & $C_{2}=607,200$ \\
\hline & $\mathrm{Y}_{3}$ (North Delhi) & 22 & $C_{3}=580,800$ \\
\hline & $\mathrm{Y}_{4}$ (West Delhi) & 22 & $C_{4}=580,800$ \\
\hline & $\mathrm{Y}_{5}$ (Gurugram) & 23 & $C_{5}=607,200$ \\
\hline & $\mathrm{Y}_{6}$ (Noida) & 21 & $C_{6}=554,400$ \\
\hline
\end{tabular}

Appendix B: Volume of items returned daily by customer indexes

\begin{tabular}{|c|c|c|c|}
\hline Customer Index & Volume of items returned daily $\left(\mathbf{V}_{\mathbf{i}}\right)$ & Customer Index & $\begin{array}{c}\text { Volume of items returned daily } \\
\left(\mathbf{V}_{\mathbf{i}}\right)\end{array}$ \\
\hline 1 & $\mathrm{~V}_{1}=98$ & 11 & $\mathrm{~V}_{11}=74$ \\
\hline 2 & $\mathrm{~V}_{2}=95$ & 12 & $\mathrm{~V}_{12}=70$ \\
\hline 3 & $\mathrm{~V}_{3}=94$ & 13 & $\mathrm{~V}_{13}=66$ \\
\hline 4 & $\mathrm{~V}_{4}=92$ & 14 & $\mathrm{~V}_{14}=80$ \\
\hline 5 & $\mathrm{~V}_{5}=90$ & 15 & $\mathrm{~V}_{16}=75$ \\
\hline 6 & $\mathrm{~V}_{6}=88$ & 16 & $\mathrm{~V}_{17}=64$ \\
\hline 7 & $\mathrm{~V}_{7}=92$ & 17 & $\mathrm{~V}_{18}=62$ \\
\hline 8 & $\mathrm{~V}_{8}=84$ & 18 & $\mathrm{~V}_{19}=65$ \\
\hline 9 & $\mathrm{~V}_{9}=85$ & 19 & $\mathrm{~V}_{20}=70$ \\
\hline
\end{tabular}

Appendix C: Operating days, holding time \& inventory carrying cost 
Das, et al: Designing a Reverse Logistics Network for an E-Commerce Firm: A Case Study

Operations and Supply Chain Management 13(1) pp. 48 - 63 (C) 2020

Appendix D: Unit transportation cost $\left(u_{i j}\right)$ from customer indexes (I) to ICCs $\left(\mathrm{Y}_{\mathrm{j}}\right)$

\begin{tabular}{|c|c|c|c|c|c|c|}
\hline \multirow[b]{2}{*}{ Customer index (I) } & \multicolumn{6}{|c|}{$\operatorname{ICCs}\left(Y_{j}\right)$} \\
\hline & $Y_{1}$ & $Y_{2}$ & $Y_{3}$ & $Y_{4}$ & $Y_{5}$ & $Y_{6}$ \\
\hline 1 & 28 & 32 & 32 & 33 & 40 & 39 \\
\hline 2 & 26 & 31 & 32 & 34 & 41 & 38 \\
\hline 3 & 26 & 30 & 31 & 32 & 42 & 37 \\
\hline 4 & 27 & 31 & 30 & 31 & 43 & 36 \\
\hline 5 & 30 & 26 & 33 & 31 & 37 & 38 \\
\hline 6 & 31 & 27 & 34 & 32 & 39 & 36 \\
\hline 7 & 32 & 25 & 35 & 33 & 38 & 37 \\
\hline 8 & 32 & 33 & 25 & 30 & 45 & 38 \\
\hline 9 & 31 & 34 & 26 & 31 & 44 & 37 \\
\hline 10 & 30 & 35 & 27 & 32 & 43 & 36 \\
\hline 11 & 33 & 32 & 31 & 27 & 37 & 43 \\
\hline 12 & 34 & 31 & 30 & 28 & 38 & 42 \\
\hline 13 & 32 & 33 & 30 & 26 & 39 & 41 \\
\hline 14 & 42 & 37 & 44 & 39 & 27 & 45 \\
\hline 15 & 41 & 38 & 45 & 38 & 28 & 46 \\
\hline 16 & 40 & 39 & 43 & 37 & 29 & 47 \\
\hline 17 & 39 & 35 & 38 & 41 & 47 & 25 \\
\hline 18 & 38 & 36 & 37 & 42 & 48 & 26 \\
\hline 19 & 37 & 37 & 39 & 43 & 46 & 27 \\
\hline 20 & 36 & 38 & 36 & 44 & 45 & 28 \\
\hline
\end{tabular}

Appendix E: Unit transportation cost $\left(u_{j k}\right)$ from ICCs $\left(\mathrm{Y}_{\mathrm{j}}\right)$ to final warehouse

\begin{tabular}{|c|c|c|c|}
\cline { 2 - 4 } \multicolumn{1}{c|}{$Y_{j}$} & $K 1$ & $K 2$ & $K 3$ \\
\hline$Y_{1}$ & 53 & 97 & 83 \\
\hline$Y_{2}$ & 52 & 96 & 82 \\
\hline$Y_{3}$ & 55 & 98 & 84 \\
\hline$Y_{4}$ & 51 & 95 & 81 \\
\hline$Y_{5}$ & 50 & 96 & 82 \\
\hline$Y_{6}$ & 58 & 100 & 85 \\
\hline
\end{tabular}

Appendix F: Multiplication factor (f) according to holding period in the ICCs

\begin{tabular}{|c|c|}
\hline Holding Time $(\mathbf{t})$ & Multiplication Factor (f) \\
\hline $\mathrm{t}=2$ & 1.4 \\
\hline $\mathrm{t}=3$ & 1.3 \\
\hline $\mathrm{t}=4$ & 1.2 \\
\hline $\mathrm{t}=5$ & 1.1 \\
\hline $\mathrm{t}=6$ & 1.0 \\
\hline $\mathrm{t}=7$ & 0.9 \\
\hline
\end{tabular}

Appendix G.1: Maximum number of returns (P) and minimum number of returns (Q)

Base Model:

$$
\begin{aligned}
& P=1652 \\
& Q=660
\end{aligned}
$$

Appendix G.2: Values of $\mathrm{P}$ and $\mathrm{Q}$ with respect to the variation in $\mathrm{V}_{\mathrm{i}}$

\begin{tabular}{|c|c|c|c|c|c|c|c|c|}
\hline \multirow{2}{*}{ Capacity } & \multicolumn{7}{|c|}{ Change in $\mathbf{V}_{\mathbf{i}}$} \\
\cline { 2 - 9 } & $\mathbf{- 2 0 \%}$ & $\mathbf{- 1 5 \%}$ & $\mathbf{- 1 0 \%}$ & $\mathbf{- 5 \%}$ & $\mathbf{+ 5 \%}$ & $\mathbf{+ 1 0 \%}$ & $\mathbf{+ 1 5 \%}$ & $\mathbf{+ 2 0 \%}$ \\
\hline $\mathbf{P}$ & 1322 & 1405 & 1487 & 1570 & 1735 & 1818 & 1900 & 1983 \\
\hline $\mathbf{Q}$ & 529 & 562 & 594 & 628 & 694 & 727 & 760 & 793 \\
\hline
\end{tabular}


Appendix G.3: Values of $\mathrm{P}$ and $\mathrm{Q}$ with respect to the variation in $\mathrm{t}$

\begin{tabular}{|c|c|c|c|c|c|}
\hline \multirow{2}{*}{ Capacity } & \multicolumn{5}{|c|}{ Change in $\mathrm{t}$} \\
\hline & $t=2$ & $t=3$ & $t=5$ & $t=6$ & $t=7$ \\
\hline $\mathbf{P}$ & 826 & 1240 & 2066 & 2478 & 2892 \\
\hline $\mathbf{Q}$ & 330 & 496 & 826 & 990 & 1156 \\
\hline
\end{tabular}

Appendix G.4: Values of $\mathrm{P}$ and $\mathrm{Q}$ with respect to change in $\mathrm{t}$ and $\mathrm{V}_{\mathrm{i}}$

\begin{tabular}{|c|c|c|c|c|c|c|}
\hline \multicolumn{2}{|c|}{ 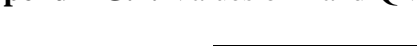 } & \multicolumn{5}{|c|}{ Change in $V_{i}$} \\
\hline & Capacity & $+10 \%$ & $+20 \%$ & $+30 \%$ & $+40 \%$ & $+50 \%$ \\
\hline \multirow[t]{2}{*}{ For $\mathrm{t}=2$} & $\mathrm{P}$ & 910 & 992 & 1074 & 1156 & 1240 \\
\hline & $Q$ & 364 & 396 & 430 & 462 & 496 \\
\hline \multirow[t]{2}{*}{ For $\mathrm{t}=3$} & $\mathrm{P}$ & 1363 & 1487 & 1612 & 1735 & 1858 \\
\hline & Q & 545 & 594 & 644 & 694 & 743 \\
\hline \multirow[t]{2}{*}{ For $\mathrm{t}=4$} & $P$ & 1818 & 1982 & 2148 & 2313 & 2478 \\
\hline & $Q$ & 727 & 792 & 859 & 925 & 991 \\
\hline \multirow[t]{2}{*}{ For $\mathrm{t}=5$} & $P$ & 2272 & 2478 & 2685 & 2892 & 3098 \\
\hline & Q & 908 & 991 & 1074 & 1156 & 1239 \\
\hline \multirow[t]{2}{*}{ For $\mathrm{t}=6$} & $P$ & 2726 & 2974 & 3222 & 3470 & 3718 \\
\hline & $Q$ & 1090 & 1189 & 1288 & 1388 & 1487 \\
\hline
\end{tabular}

Appendix G.5: Values of P and Q with respect to the variation in the number of ICCs

\begin{tabular}{|c|c|c|c|c|}
\hline \multirow{2}{*}{ Capacity } & \multicolumn{4}{|c|}{ Change in the number of ICCs } \\
\cline { 2 - 5 } & ICC = 2 & ICC = 3 & ICC = 5 & ICC = 6 \\
\hline P & 3305 & 2203 & 1322 & 1102 \\
\hline $\mathbf{Q}$ & 1322 & 881 & 528 & 440 \\
\hline
\end{tabular}

\section{REFERENCES}

Ali, S.M., and Nakade, K. (2015). A mathematical optimization approach to supply chain disruptions management considering disruptions to suppliers and distribution centers. Operations and Supply Chain Management, 8 (2), pp. 57 66.

Atlason, R.S., D. Giacalone, and K.Parajuly.(2017). Product design in the circular economy: Users' perception of end-of-life scenarios for electrical and electronic appliances. Journal of Cleaner Production, 168,pp. 1059 - 1069.

Blackburn, J.D., V.D.R.Guide Jr., G.C. Souza, and L.N. Van Wassenhove.(2004).Reverse supply chains for commercial returns. California Management Review, 46 (2), pp.6-22.

Bold Metrics Blog.(2016). Apparel retailers start 2016 with a 30\% return rate. Available in http://blog.boldmetrics.com/apparelretailers-start-2016-with-a-30-return-rate/ accessed June 20, 2018.

Chen, C., S. Pan, Z. Wang, and R. Y. Zhong.(2017). Using taxis to collect citywide e-commerce reverse flows: a crowdsourcing solution. International Journal Production Research, 55(7),pp. $1833-1844$.

Chopra, S., and Kalra, D.(2019).Supply Chain Management: Strategy, Planning and Operation, Pearson India Education Services Pvt. Ltd., $7^{\text {th }}$ edition, Noida, India.

deBrito, M.P.,and Dekker, R.(2003). A framework for reverse logistics. ERIM Report Series Reference No. ERS-2003-045LIS.

Das, D., and Chaudhari, R. (2015). Reverse supply chain management in consumer electronics: An Indian perspective. International Journal of Logistics Systems and Management, 20 (3), pp. $348-369$.

Das, D., Rajak, M.K., and Kumar, R. (2018). Reverse logistics network design for an e-commerce firm. Proceedings of the $2^{\text {nd }}$ European Conference on Industrial Engineering and Operations Management (IEOM) Paris, July 26 - 27, 2018, pp.757- 758 .

Dissanayake, D., and Singh, M. (2007). Managing Returns in EBusiness. Journal of Internet Commerce, 6 (2), pp. 35-49.

Dowlatshahi, S. (2000). Developing a theory of reverse logistics. Interfaces 30 (3),143-155.
E-commerce Product Return Statistics and Trends (Info graphic), 2016. Available

https://www.business2community.com/infographics/ecommerce-product-return-statistics-trends-infographic 01505394\#ijIGsYIOR2WxsPh3.97 accessed January 25, 2018.

E-tailers change return policies in the bid to cut down losses.(2015).Available

https://indianonlineseller.com/2015/04/etailerschangereturn-policies-in-the-bid-to-cut-down-losses/ accessed April 30, 2017.

Guide Jr., V.D.R. (2000). Production planning and control for remanufacturing: industry practice and research needs. Journal of Operations Management, 18 (4), pp. 467-483.

Guide Jr., V.D.R., Jayaraman V., Srivastava R., and Benton W. C. (2000). Supply chain management for recoverable manufacturing systems. Interfaces 30 (3),pp.125-142.

Guide Jr., V.D.R., Souza, G.C., Van Wassenhove, L.N., and Blackburn, J. D.(2006). Time value of commercial product returns. Management Science, 52 (8),pp. 1200-1214.

Guide Jr., V.D.R., and Van Wassenhove, L.N. (2009).The evolution of closed-loop supply chain Research. Operations Research, 57 (1),pp. 10-18.

Hjort, K., and Lantz, B.(2016). The impacts of returns policies on profitability: A fashion e-commerce case. Journal of Business Research, 69 (11),pp. 4980 - 4985.

KPMG report: E-commerce retail logistics in India.(2018). Available

https://assets.kpmg/content/dam/kpmg/in/pdf/2018/05/ecommerce-retail-logistics.pdf accessed April 30, 2019.

Kokkinaki, A.I.,Dekker,R., Nunen, J. van, and Pappis, C. (2000). An Exploratory Study on Electronic Commerce for Reverse Logistics. Supply Chain Forum: An International Journal, 1 (1), pp. 10-17.

Lau, K.H., and Wang, Y. (2009). Reverse logistics in the electronic industry of China: a case study. Supply Chain Management: an International Journal,14 (6),pp. 447-465.

Liu, D. (2014). Network site optimization of reverse logistics for ecommerce based on genetic algorithm. Neural Computing and Applications, 25 (1),pp. $67-71$. 
Mokrini, A. E., Boulaksil, Y., and Berrado, A. (2019). Modelling facility location problems in emerging markets: The case of the public healthcare sector in Morocco. Operations and Supply Chain Management, 12 (2), pp. 100 - 111.

Mukhopadhyay, S.K., and Setoputro, R.(2004). Reverse logistics in e-business: Optimal price and return policy. International Journal of Physical Distribution \& Logistics Management, 34 (1),pp. $70-89$.

Pan, S., Chen, C.and Zhong, R. Y. (2015). A crowdsourcing solution to collect e-commerce reverse flows in metropolitan areas. IFAC Papers Online, 48 (3),pp. 1984 - 1989.

Ramanathan, R. (2011). An empirical analysis on the influence of risk on relationships between handling of product returns and customer loyalty in e-commerce. International Journal of Production Economics, 130, pp. 255 - 261.

Rogers, D.S., and Tibben-Lembke,R.S. (1999).Going Backwards: Reverse Logistics Trends and Practices, RLEC Press, Pittsburgh, PA.

Rogers, D.S., and Tibben-Lembke, R. S. (2001). An examination of reverse logistics practices. Journal of Business Logistics, 22 (2),pp. 129-148.

Savaskan, R.C., Bhattacharya,S. andVan Wassenhove,L.N. (2004). Closed loop supply chain models with product remanufacturing. Management Science, 50 (2),pp. 239-252.

Share of consumers who returned items in 2016, by type of item. Available https://www.statista.com/statistics/754320/most-returneditems-reverse-logistics/ accessed June 30, 2018.

Shipping rate calculator for e-Commerce Couriers(Domestic) Shiprocket. Available in https://www.shiprocket.in/shippingrate-calculator/ accessed July 5, 2018.

Simchi-Levi, D., Kaminsky, P.,Simchi-Levi, E., and Shankar, R. (2008). Designing and Managing the Supply Chain: Concepts, Strategies and Case Studies Tata McGraw Hill, $3^{\text {rd }}$ ed., Delhi.

Tanskanen, P. (2012). Electronics Waste: Recycling of Mobile Phones, Post-Consumer Waste Recycling and Optimal Production. Prof. Enri Damanhuri (Ed.), In Tech, Available from: http://www.intechopen.com/books/post-consumerwaste-recycling-and-optimal-production/electronicswasterecycling-of-mobile-phones
The Economic Times, Oct 5, 2015. Flipkart may spend $\$ 500$ million to add 50-100 warehouses in next 5 years. Available in https://economictimes.indiatimes.com/industry/services/retai 1/flipkart-may-spend-500-million-to-add-50-100warehouses-in-next-5-years/articleshow/49220186.cms accessed June 15, 2017.

The Economic Times, Jan 17, 2018.Fashion ecommerce firms like Flipkart, Myntra uncover fake product returns. Available in https://economictimes.indiatimes.com/smallbiz/startups/new sbuzz/fashion-ecommerce-firms-like-flipkart-myntra uncover-fake-product-returns/articleshow/62533363.cms accessed June 4, 2019.

The Indian Express, April 6, 2018. E-commerce firms losing over 30 percent GMV due to cancellations/returns. Available in https://indianexpress.com/article/business/business-others/ecommerce-firms-losing-over-30-per-cent-of-gmv-due-tocancellations-returns-5125471/ accessed June 4, 2019.

Toffel, M.W. (2004). Strategic management of product recovery. California Management Review, 46 (2),pp. 120-138.

Wang, W. (2015). A decision method for returns logistics based on the customer's behavior in e-commerce. Procedia Computer Science, 60, pp. $1506-1515$.

Weltevreden, J.(2008). B2c e-commerce logistics: the rise of collection and delivery points in the Netherlands. International Journal of Retail \& Distribution Management, 36 (8),pp. $638-660$.

Weraikat, D, Zanjani,M.K., and Lehoux,N. (2016). Two-echelon pharmaceutical reverse supply chain coordination with customers incentives. International Journal of Production Economics, 176, pp. $41-52$.

XiaoYan, Q., Yong,H.,Qinli, D., and Stokes, P.(2012). Reverse logistics network design model based on e-commerce. International Journal of Organizational Analysis, 12 (2),pp. $251-261$.

Zaarour, N., Melachrinoudis,E., Solomon, M., and Min, H. (2014). A reverse logistics network model for handling returned products. International Journal of Engineering Business Management, 6 (13), $1-10$. Available in https://journals.sagepub.com/doi/pdf/10.5772/58827

Debadyuti Das is a Professor at Faculty of Management Studies, University of Delhi. He holds a Ph.D. in Industrial Management from IIT BHU and Masters in Industrial Engineering \& Management from ISM, Dhanbad He has a rich blend of experience in both industry and academics spanning over more than two decades. His areas of specialization include Production \& Operations Management, Supply Chain Management etc. His research papers have appeared in various journals of repute including International Journal of Production Research, International Journal of Project Management, Journal of Cleaner Production, International Journal of Services \& Operations Management, International Journal of Logistics Systems \& Management, International Journal of Tourism Policy, International Journal of Energy Sector Management, IIMB Management Review, etc. His current research interests include Sustainable Supply Chain Management, Issues in Reverse Logistics in both traditional and e-commerce firms, Carbon Footprints in supply chain, Optimization of Power Procurement, Supply Chain issues in Public Health etc. He is a member of POMS, USA and SOM, India.

Rahul Kumar is currently pursuing his Ph.D. from Faculty of Management Studies, University of Delhi. Earlier he completed his M.Sc. and M. Phil in Operational Research from the Department of Operational Research, Faculty of Mathematical Sciences, University of Delhi. He has published research papers in several journals of repute including International Journal of Energy Sector Management, International Journal of Reliability and Safety etc. He is currently pursuing research on Distribution Network Design in Public Health.

Manish Kumar Rajak, an MBA from Faculty of Management Studies, University of Delhi, is currently working as Manager at ShopClues, Gurugram, India. ShopClues is an online marketplace owned by Clues Network Pvt. Ltd. Mr. Manish is leading and managing a large team of professionals for improving merchant experience in ShopClues. He is responsible for maximizing merchant operational performance by providing technical advice and resolving problems within SLA. He is also responsible for improving merchant service quality results by studying, evaluating and re-designing processes; establishing service metrics; monitoring and analyzing results and finally implementing changes. 